7. Reprod. Fert. (1966) 11, 27-32

\title{
THE EFFECT OF AN IUFB ON REPRODUCTION IN MICE
}

\author{
LEE LEE DOYLE AND ALAN J. MARGOLIS \\ Department of Obstetrics and Gynecology, \\ University of California School of Medicine, San Francisco, \\ California, U.S.A.
}

(Received 11th March 1965)

\begin{abstract}
Summary. Adult female mice with an intra-uterine foreign body in one horn were mated to normal males. Females were killed on Days 2 to 11, the reproductive tracts were removed, implantations were counted and the uteri and tubes were flushed to recover unimplanted ova. None of the thirty-two females killed after Day 5 had any evidence of implantations in the operated horn, and only $28 \%$ had implantations in the control horn. Forty-five per cent of these females had an average of 3.9 ova in the tubes of the operated side at this time, a finding which could not be explained by any gross anatomical alteration. Fifteen animals killed prior to implantation confirmed the fact that sperm transport and fertilization did occur in both operated and control sides, but that tubal transport of ova was altered on the operated side. All of the ova remained in the tube on Day 4 when ova on the control side were recovered from the uterus.
\end{abstract}

\section{INTRODUCTION}

The past 3 years have seen a renaissance of interest in the intra-uterine device as a means of birth control in humans. Renewed use of this method has led in turn to efforts to determine the mechanism of action in preventing pregnancy. Since direct experiment on a large scale is virtually impossible in humans, studies have been carried out using model systems in subhuman primates and lower mammals.

Results from investigations in rabbits (Carleton \& Phelps, 1933; Marston \& Chang, 1964; Eckstein \& Adams, 1964), rats (Doyle \& Margolis, 1963; Kar, Kamboj \& Datta, 1964; Chaudhury, 1964; Marston \& Chang, 1964), ruminants (Hawk, Conley, Brinsfield \& Righter, 1964), and monkeys (Mastroianni \& Hongsonand, 1964) have shown that although an IUFB is effective in varying degrees in all these species, the time and mode of action differ. The animals studied thus far, however, also differ widely in one or more aspects of their reproductive anatomy and/or physiology. This study was designed to determine if two more closely allied species would react in similar fashion to an IUFB, and it was to this purpose that investigations we had completed in rats (Doyle \& Margolis, 1964; Margolis \& Doyle, 1964) were repeated using mice. 


\section{MATERIALS AND METHODS}

Mature females of one of three strains (Swiss-Webster, C57BL or R3) chosen at random stages in the oestrous cycle were anaesthetized with ether, and one uterine horn was exposed through a dorsolateral incision. An atraumatic needle with 5-0 braided silk suture was put through the anti-mesometrial wall, passed along the lumen and brought out 4 to $6 \mathrm{~mm}$ below the original point of insertion. A knot in the upper end of the suture, external to the uterine horn, held the suture in place. The lower end of the suture was clipped at the point of exit so that the suture would fall free in the lumen. The incisions were closed, usually with a single suture, the animals placed with males and examined each morning subsequently for the presence of a copulation plug; at this time females usually were placed in another cage. The day a plug was found was called Day 1 of pregnancy. Animals were killed on Days 2 to 11 and the entire reproductive tract was dissected out. Animals killed after Day 4 were checked visually and in some cases histologically for number of implantations, and in most animals the uterus and tubes were flushed to determine if ova were present. The tubes were separated from the uterine horns at the uterotubal junction and the uterine horns were then flushed separately by placing a 25 gauge needle through each cervix and injecting approximately $1 \mathrm{ml}$ of a balanced salt solution. In order to flush the tubes, a 30 gauge needle was introduced into the fimbriated end of the tube, and held in place with watchmaker's forceps while the flushing solution was injected. The uterine horns could be flushed easily without the aid of any magnification, but the tubes were placed in a drop or two of the salt solution which made the fimbria more easily visualized, and flushed under a dissecting microscope. The uterine and tubal washings were examined under a binocular dissecting microscope at $\times 50$ magnification, and the number, stage of cleavage and condition of ova were noted.

\section{RESULTS}

The animals were divided into three groups according to strain so that any variance due to genetic differences would not obfuscate the results.

Variability in strain and age of both males and females and in mating procedures precludes any conclusion regarding alteration of the oestrous cycle. Some groups seemed to show an increased incidence of prolonged or aberrant cycles while others appeared unaffected; however, the IUFB did not, in any case, cause complete cessation of oestrous cycles.

The efficacy of an IUFB in preventing pregnancy in mice is shown in Table 1. All thirty-two females which had an IUFB in place at the time of autopsy had failed to implant in the operated horn, while nine $(28 \%)$ had implantations in the control horn. In four animals in which the suture was not present at the time of autopsy (Days 5 to 11), two had bilateral implants, a third had blastocysts in the operated horn on Day 6, while the fourth had neither ova nor implantations.

Five females, which were intact and bred to normal males, were killed on 


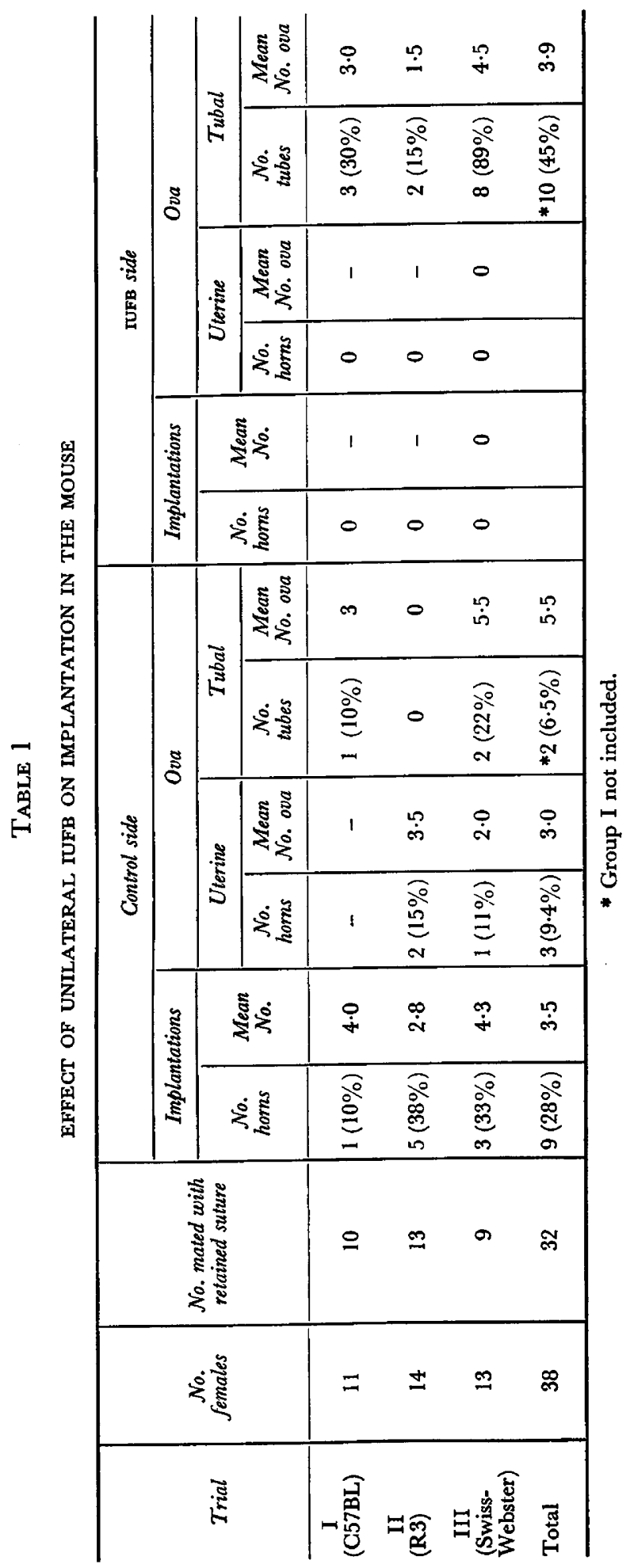


Days 8 to 10 as controls. Four of these had bilateral implantations with an average of 6.3 implants in the left and 6.0 implants in the right horn.

Despite the fact that all animals listed in Table 1 were killed after implantation, a time when no free ova should have been present, ova were recovered from both the uterus and tubes of the control side and from the tubes of the operated side as shown in Table 1. Trial I animals were not included in computing the ova recovery averages since not all animals were checked for the presence of unimplanted ova. Of the twenty-three animals without implantations on the control side, three $(13 \%)$ had uterine ova on that side (one of these females had an implantation site as well), and two $(8.8 \%)$ had tubal ova. All tubal ova from the control side were abnormal, but only two of the nine uterine ova appeared abnormal. Comparable data for the twenty-two operated horns in Groups II and III show that no uterine ova could be recovered, but ten $(45 \%)$ of the females had tubal ova. Of the thirty-nine ova recovered, nine $(23 \%)$ appeared to be normal blastocysts. Seven of the nine had shed

TABLE 2

EFFECT OF AN IUFB ON PRE-IMPLANTATION EVENTS IN THE MOUSE

\begin{tabular}{|c|c|c|c|c|c|c|c|}
\hline \multirow{3}{*}{$\begin{array}{c}\text { Day } \\
\text { autopsy }\end{array}$} & \multirow{3}{*}{$\begin{array}{c}\text { No. } \\
\text { females }\end{array}$} & \multicolumn{3}{|c|}{ Control side } & \multicolumn{3}{|c|}{ IUFB side } \\
\hline & & \multirow[b]{2}{*}{ Uterine ova } & \multicolumn{2}{|c|}{ Tubal ova } & \multirow[b]{2}{*}{ Uterine ova } & \multicolumn{2}{|c|}{ Tubal ova } \\
\hline & & & Normal & $\begin{array}{l}\text { Abnormal or } \\
\text { uncleaved }\end{array}$ & & Normal & $\begin{array}{l}\text { Abnormal or } \\
\text { uncleaved }\end{array}$ \\
\hline $\begin{array}{l}2 \\
3 \\
4\end{array}$ & $\begin{array}{l}5 \\
5 \\
5\end{array}$ & $\begin{array}{r}0 \\
0 \\
27\end{array}$ & $\begin{array}{r}26 \\
12 \\
1\end{array}$ & $\begin{array}{r}1 \\
20 \\
0\end{array}$ & $\begin{array}{l}0 \\
0 \\
0\end{array}$ & $\begin{array}{r}8 \\
12 \\
22\end{array}$ & $\begin{array}{r}20 \\
10 \\
1\end{array}$ \\
\hline
\end{tabular}

their zonae and appeared very similar to ova found in the uterus of animals in which implantation had been delayed.

Fifteen animals were killed during the pre-implantation period, and the results of ova recovery from these animals are shown in Table 2 . Only tubal ova could be recovered from either side on Days 2 and 3, while on Day 4 ova were recovered from the uterus on the control side but only from the tube on the operated side.

\section{DISCUSSION}

The effect of an IUFB in one uterine horn of a mouse is not so sharply delineated in time and site of action as it is in the rat. The ultimate result, inhibition of pregnancy in the operated horn, is comparable in mice and rats, but the mode of action may be totally different.

One of the findings which was most unexpected was the relatively low number of animals with implantations in the control horn. Four of the five control animals had bilateral implantations, but only $28 \%$ of the operated animals had implants in the control horns. A number of explanations such as inadequate spermatozoal transport resulting in failure of fertilization, abnormal 


\section{PLATE 1}
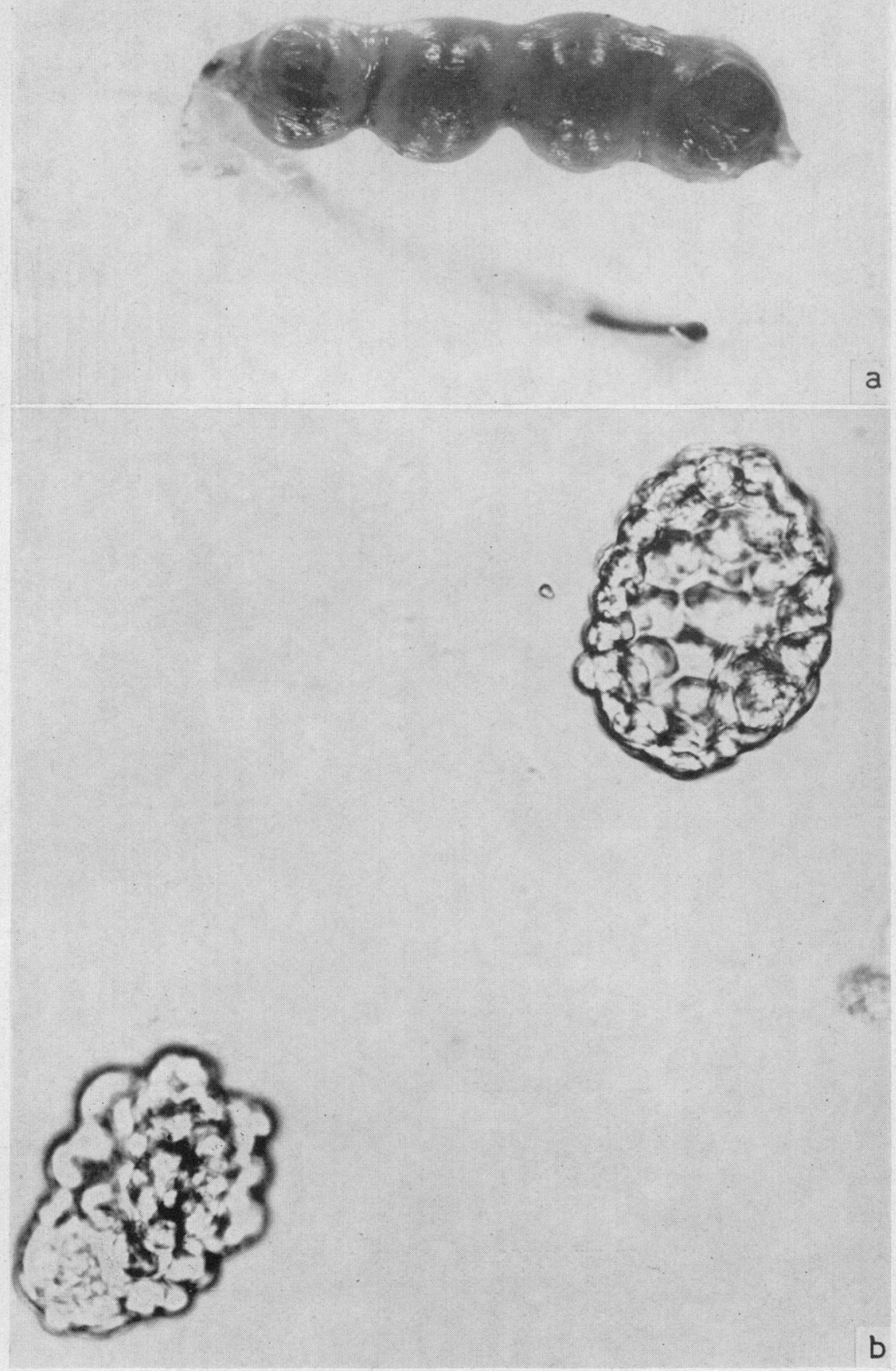

(a) Uterus from mouse with unilateral IUFB on Day 11 of gestation.

(b) Blastocysts recovered from tube on IUFB side of mouse in (a). $\times 200$.

(Facing p. 30) 
transport of ova or aberrant uterine motility could account for this phenomenon; however, no matter what the cause, it was apparent that the effect of an IUFB in mice was not limited to the operated horn as it was in the rat.

The lack of implantation in the operated horn was easier to understand. As in the rat, the ova simply were not present in the uterus at the time implantation occurred. Unlike the rat, in mice ova often remained in the tube on the IUFB side. Animals with normal implantations in the control horn often had normal, unimplanted blastocysts in the tube on the IUfB side (Plate 1, a and b). Although ova were found in the tubes of less than $50 \%$ of the females killed after implantation, all five animals killed on Day 4 had uterine ova on the control side, but tubal ova on the operated side. Mechanical blockage of the uterotubal junction probably did not cause the retention of ova since some ova were fertile, proving that spermatozoal transport had occurred normally, and there was no tubal distension due to fluid accumulation which would have been expected if the junction were completely closed.

Alterations in tube transport of ova have been reported in monkeys and cattle (Hawk et al., 1964; Mastroianni \& Hongsonand, 1964) which have an IUFB in place, but in both cases the ova, rather than being delayed in passage, were thought to be speeded up as they could not be found in the tubes at times when they could be recovered routinely in control females. The phenomenon of 'tube locking' is not unknown in rodents, but it has been artificially precipitated by administration of hormones (Greenwald, 1961). Surprisingly little is known regarding tubal physiology and the actual mechanics of normal tubal transport of ova in most species though many facets of the subject are being studied.

Although preimplantation ova recoveries seem to indicate a high percentage of either abnormal or uncleaved ova on Day 3, it is probably due to the fact that four out of five of these females mated immediately following surgery when conditions for spermatozoal transport may have been less than ideal. Certainly the data from Day 4 indicate that the IUFB had no effect on fertilization of ova generally. The high incidence of uncleaved ova on Day 2 on the IUFB side may indicate that spermatozoal transport is slower in the uterine horn with an IUFB in place and, had the animals been killed later in the day, the ova might have been cleaved.

Like the rat, the mouse may also react to the presence of an IUFB with an altered uterine environment which is incompatible with normal implantation. If we postulate that this altered environment is due to abnormal endometrial secretions, we can then explain how the IUFB can have a more than local effect in mice. Dye injected into one horn of a mouse will fill that horn and pass through a small opening into the contralateral horn so it is possible that endometrial secretions might also pass from one horn to the other.

We may conclude that an IUFB prevents implantation in the operated horn of the mouse as well as the rat, although in the former rodent its effects are multiple and bilateral. Passage of ova from the tube of the operated side may be impeded and implantation may be prevented in the control horn. The most likely explanation for this latter phenomenon is that the endometrial lumen of the operated horn contains products inimicable to normal implantation and 
these products are communicated to the control horn by a small connection between the horns. Why and how the IUFB in some cases affects tubal transport is a fascinating problem that remains unsolved.

\section{REFERENCES}

Carleton, H. M. \& Phelps, H. J. (1933) Birth control studies. III. Experimental observations on the Grafenberg ring contraceptive methods. F. Obstet. Gynaec. Br. Emp. 40, 81.

Chatdhury, R. R. (1964) Effect of intra-uterine silk thread suture on fertility of female rats. IInd int. Conf. Intra-Uterine Contraception, New York.

Doyle, L. L. \& MARgolis, A. J. (1963) Intrauterine foreign body. Effect on pregnancy in the rat. Science, N.T. 139, 833.

Doyle, L. L. \& MARGolis, A. J. (1964) Intrauterine foreign body. I. Effect on reproductive processes in the rat. Fert. Steril. 15, 597.

Eckstein, P. \& Adams, C. E. (1964) Effect of intrauterine devices on gestation in rabbits. IInd int. Conf. Intra-Uterine Contraception, New York.

Greenwald, G. A. (1961) Study of the transport of ova through the rabbit oviduct. Fert. Steril. 12, 80.

Hawk, H. W., Conley, H., Brinsfield, T. H. \& Righter, H. F. (1964) Contraceptive effect of plastic devices in cattle uteri. Ind int. Conf. Intra-Uterine Contraception, New York.

Kar, A. B., Kamboj, V. P. \& Datta, J. K. (1964) Prevention of delayed implantation in rats by means of an intrauterine foreign body. F. Reprod. Fert. 8, 139.

Margolis, A. J. \& Doyle, L. L. (1964) Intrauterine foreign body. II. Inhibition of decidual response in the rat. Fert. Steril, 15, 607.

Marston, J. H. \& Chang, M. C. (1964) Experiments on the action of intrauterine foreign bodies in the rat. Ind int. Conf. Intra-Uterine Contraception, New York.

Marston, J. H. \& Chang, M. C. (1964) The action of an intrauterine foreign body in the rabbit. Ind int. Conf. Intra-Uterine Contraception, New Tork.

Mastroianni, L. \& Hongsonand, C. (1964) Mechanism of action of the intrauterine contraceptive device in the primate. 1. Tubal transport of ova and distribution of spermatozoa. IInd int. Conf. Intra-Uterine Contraception, New Tork. 